\title{
REVIEW ARTICLE \\ A review of bovine tuberculosis at the wildlife-livestock-human interface in sub-Saharan Africa
}

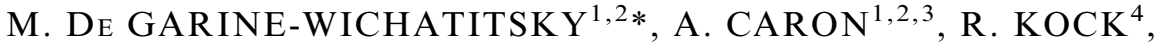

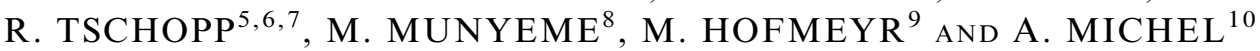 \\ ${ }^{1}$ Cirad, UPR AGIRs, Montpellier, France \\ ${ }^{2}$ Cirad/RP-PCP, Harare, Zimbabwe \\ ${ }^{3}$ Mammals Research Institute, University of Pretoria, Pretoria, South Africa \\ ${ }_{5}^{4}$ Royal Veterinary College, University of London, UK \\ ${ }^{5}$ Swiss Tropical and Public Health Institute, Basel, Switzerland \\ ${ }^{6}$ Armauer Hansen Research Institute, Addis Ababa, Ethiopia \\ ${ }^{7}$ MRC National Institute for Medical Research, London, UK \\ ${ }^{8}$ Department of Disease Control, University of Zambia, School of Veterinary Medicine, Lusaka, Zambia \\ ${ }^{9}$ South Africa National Parks, Kruger National Park, South Africa \\ ${ }^{10}$ Department of Veterinary Tropical Diseases, Faculty of Veterinary Science, University of Pretoria, Pretoria, \\ South Africa
}

Received 31 October 2012; Final revision 21 February 2013; Accepted 27 February 2013; first published online 15 April 2013

\section{SUMMARY}

Infection of wild animals by bovine tuberculosis (bTB) is raising concern worldwide. This article reviews the current epidemiological situation, risk of emergence and control options at the wildlife-livestock-human interface in sub-Saharan Africa. In livestock, bTB has been confirmed in the majority of countries from all parts of the continent. Wildlife infection is confirmed in seven countries from southern and eastern Africa, apparently spreading in the southern Africa region. Mycobacterium bovis has been isolated from 17 wild mammal species, although only four are suspected to play a role as maintenance host. Zoonotic risks are a concern, but no direct spillover from wildlife to humans has been documented, and no case of bTB spillback from wildlife to livestock has been confirmed. In this paper we assess the main risk factors of bTB spillover at the wildlife-livestock-human interface and suggest several research themes which could improve the control of the disease in the African context.

Key words: Host (in infections), infectious disease epidemiology, spread of disease, tuberculosis (TB), zoonoses.

\section{INTRODUCTION}

Infection of wild animals by bovine tuberculosis (bTB), caused by Mycobacterium bovis, is raising concern worldwide. The pathogen has been demonstrated to infect a large number of free-ranging mammals

\footnotetext{
* Author for correspondence: Dr M. de Garine-Wichatitsky, CIRAD/RP-PCP, P.O. Box 1378, Harare Zimbabwe.

(Email: degarine@cirad.fr)
}

across different ecosystems, often characterized by relatively moist conditions, such as North American forests [1], insular ecosystems in the Pacific [2] and Great Britain [3], but also including drier ecosystems such as the Iberian peninsula [4] and semi-arid savannahs in Africa [5]. The importance of bTB infection in wild animals relates to four aspects: (i) conservation issues, as the disease may negatively impact on wild mammal populations, including endangered species, (ii) impact on livestock productions, as some wild 
species can maintain TB and act as a reservoir of the pathogen for livestock, (iii) impact on public health, with wildlife acting as a reservoir of infection either directly or through livestock and (iv) economic impacts on private game ranchers. So far, more than 60 wild mammal species worldwide have been shown to be infected with $M$. bovis [6, 7], although only a few have been demonstrated to play the role of maintenance hosts. The best known examples of the important constraint that wild free-ranging hosts may represent for eradication of bTB are the European badger (Meles meles) in the UK and the Republic of Ireland [8, 9] and the possum (Trichosurus vulpecula) in New Zealand [10, 11].

The first reported diagnosis of $M$. bovis infection in African free-ranging wild mammals was during the 1920s [12, 13], followed by the confirmation of the African buffalo (Syncerus caffer), as a maintenance host during the late 1990s [14]. But it is unclear when African wildlife first became exposed to the pathogen. Until recently it was believed that the origin of bTB in Africa was associated with the importation of infected cattle mainly from Europe and other continents, essentially during the past three centuries. New studies have revealed the existence of at least three clonal complexes of $M$. bovis which each appears to occur predominantly or exclusively in a geographically localized region of the world. The presence of M. bovis strains belonging to the European 1 clonal complex in South Africa, Tanzania and Zambia may therefore indeed be explained by historical livestock trade links between the UK and these African countries [15]. Two additional clonal complexes, African 1 [16] and African 2 [17], have been detected in several countries in West-central and East Africa, respectively, but very rarely outside Africa. The origin of these two M. bovis complexes is unknown and there is a possibility that their progenitors evolved in cattle in Africa any time between the appearance of classic M. bovis over 2000 years ago [18, 19] and colonial times [20]. Given current knowledge we cannot exclude the possibility that the exotic status of bTB in the indigenous African cattle population may have to be re-considered, at least in some subpopulations. It is therefore not possible to place the first M. bovis exposure of immunologically naive freeranging African wildlife populations within a defined time period, but it was likely sporadic in nature with little or no chance of co-evolution [21]. Given the exceptional diversity of African wild mammal species, especially ruminants, presumed to be immunologically naive to the infection, the disease might spillover to wild African species, especially those that are taxonomically related to the domestic bovid reservoir host.

Livestock and wildlife have co-existed for at least 6500 years in Africa [22] especially in arid and semiarid lands, often sharing the same spaces and resources [23]. However, wildlife-livestock-human interfaces in Africa have been significantly altered during recent decades, with increasing encroachment of human activities into wildlife habitats due to global (e.g. human population demography, increased movements of people and products) and regional (e.g. development of Transfrontier Conservation Areas in Southern Africa [24, 25]) dynamics. These changes in the nature, frequency and intensity of wildlifelivestock-human interactions may provide opportunities for pathogen spillover and spillback [26]. Zoonotic risks due to $M$. bovis in Africa have been a concern for more than 15 years [27]. Because African countries often lack the resources to adequately control bTB, and because there are numerous populations living at wildlife-livestock-human interfaces, bTB represents a significant risk for veterinary and public health, and for conservation in Africa $[28,29]$, if indeed the disease does spillback from wildlife to livestock under African conditions.

In this paper, we review existing and recent information on emerging bTB in wildlife in Africa, with emphasis on the epidemiology and control of the disease at the wildlife-livestock-human interface. Based on official records and published information, we first compare the current situations and management of bTB in the different African subregions, illustrated by several well documented case studies. We then assess the drivers of bTB infection in wildlife and identify the main factors likely to increase the risk of transmission to livestock ('livestock' in this review refers to all domesticated hoofstock species used for human consumption, fibre, draught, etc.) and to human populations. We conclude by identifying the main knowledge gaps and technical limitations, and suggest several areas that should be targeted by scientific research in order to improve bTB control in the African context.

\section{REGIONAL CONTEXTS FOR bTB IN WILDLIFE IN AFRICA}

\section{Overview}

According to the World Animal Health Information databases collating reports of member states regarding 
outbreaks of transboundary animal diseases to the Office International des Epizooties (OIE) [30, 31], during the period 1996-2011 the majority of African countries (38/54) reported bTB in livestock (infection or clinical disease), with an additional four countries reporting suspected infection, while only four countries that implemented general or targeted surveillance reported the absence of the disease (Fig. 1a). During the same period, bTB (clinical cases) in wildlife were confirmed in only $6 / 54$ countries, all located in southern and eastern Africa (Fig. 1b), with an additional five countries reporting suspected cases, while 11 countries that implemented general or targeted surveillance reported absence of the disease, and 33 African countries indicated unavailability of data regarding bTB in wildlife.

Bovine TB is a legally notifiable or controlled disease in livestock for several African countries, but the information regarding bTB reports in wildlife should be treated cautiously owing mainly to the absence of simple and reliable diagnostic tests, and because the veterinary services of most countries lack the financial and human resources to carry out disease surveillance in wildlife. Nevertheless, published information seems to indicate that bTB is probably widespread in livestock at the continental level $[32,33]$, whereas bTB infection of wildlife has only been confirmed in few countries of southern and eastern Africa [13, 21, 34].

\section{Southern Africa}

In southern Africa, bTB in free-ranging wildlife has been confirmed in South Africa [12, 35], Zambia [36] and Zimbabwe [37], while the presence of the infection has been suspected in African buffalo in Botswana [38] although not confirmed using gold standard techniques. Furthermore, in Botswana, Alexander et al. [39] reported the emergence of M. mungi, a new member of the M. tuberculosis complex in banded mongooses (Mungos mungo). In South Africa, bTB was first diagnosed in greater kudu (Tragelaphus strepsiceros), and small antelopes in 1929 in the Eastern Cape of South Africa [12]. In 1972, M. bovis infection was reported in Kafue lechwe antelopes (Kobus leche kafuensis), in the Lochinvar Game Reserve in Zambia [34], followed by the isolation of the pathogen from African buffalo in Gonarezhou National Park (GNP) in Zimbabwe in 2008 [37].

The introduction of bTB into these wildlife populations has been largely ascribed to spillover from domestic cattle [36, 40], with the exception of GNP where buffalo-to-buffalo transmission from the Kruger National Park (KNP) has been suggested [37]. The establishment of bTB in a free-ranging ecosystem requires that the infection is maintained by at least one wildlife reservoir which serves as source of infection to a range of spillover hosts. Maintenance host status has been shown for buffalo [14, 41] and lechwe, and suggested for greater kudu [35, 40] and possibly common warthog (Phacochoerus africanus [42]). Lions also became infected in KNP, although there is no evidence that they infect other species and could therefore be considered dead-end hosts (D. Keet, personal communication, 2012).

Transmission to wild spillover species may occur in different ways, including aerosol, ingestion and percutaneous. However, the exact mode of transmission, especially between ungulates remains poorly understood. Apart from direct transmission, which requires close contact between species, indirect transmission via environmental contamination is a possibility, although it has not been conclusively proven in Africa (see [43, 44]). In Zambia, it has been postulated that yearly seasonal floods play a role in the environmental propagation and dissemination of microorganisms (a point which needs further study and elaboration), while overcrowding of animals during lekking (mating season) with extra-large assemblages at watering points enhances the direct animalto-animal transmission due to the contagious nature of the disease [36]. Environmental transmission of bTB could occur at locations where domestic and wild animals congregate to rest, drink or feed and is supported by the pathogen's ability to survive in the environment of KNP for between 5 days and 6 weeks, depending on temperature and moisture [45]. In addition, the gregarious nature of most wild bovids with higher herd densities observed in drier seasons is thought to facilitate intraspecies transmission of $M$. bovis among wild ungulates.

In southern Africa, the interface between wildlife and domestic livestock is often defined by a game deterrent fence, restricting movement and minimizing contacts (for review see [46]), thus reducing the risk of $M$. bovis transmission. There are, however, some potentially infected species such as greater kudu and common warthog, which are capable of crossing these man-made barriers, and whose role in $M$. bovis transmission at the interface remains to be quantified. In addition, the boundaries of several conservation areas in the region are either unfenced or very 
(a)

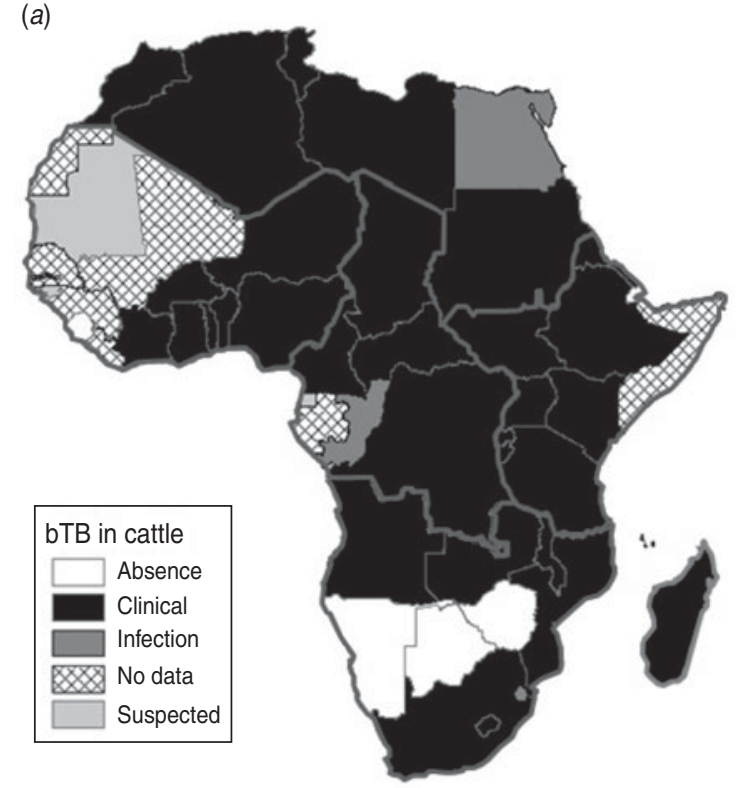

(b)

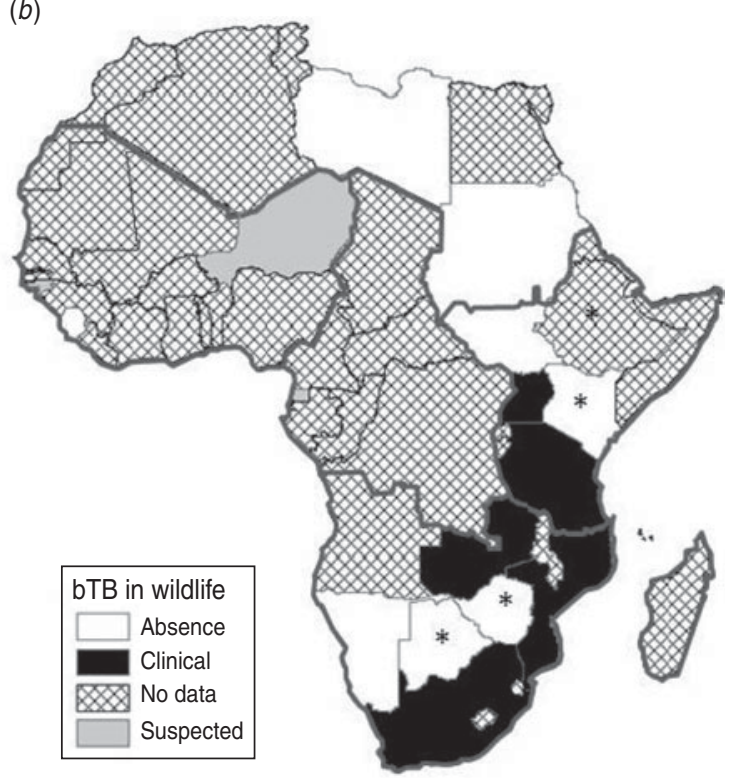

Fig. 1. Distribution map of bovine tuberculosis in Africa during 1996-2011 (large grey lines indicate the African subregions as referred to in the text: West, Central, East and Southern Africa). (a) Cattle status at country level; (b) wildlife status at country level. Asterisk $\left(^{*}\right)$ indicates countries (i.e. Botswana, Ethiopia, Kenya, Zimbabwe) where suspected and confirmed cases have been detected but not yet reported to OIE [37, 38, 50, 59, 60]. No additional information (e.g. species) was available for suspected cases reported in wildlife for Niger, Equatorial Guinea and GuineaBissau and confirmed cases in wildlife in Mozambique. Data compiled from World Animal Health Information databases/OIE [30, 31, 42] and [37, 38, 50, 59, 60].

permeable to animal movements in both directions because they have been damaged and/or are not adequately maintained. Contacts between wildlife reservoirs and livestock populations living at the periphery of transfrontier conservation areas in southern Africa, do occur and occasionally result in the transmission of wildlife-borne diseases such as corridor disease or foot-and-mouth disease (e.g. [25, 47]). Thus, there is a risk of bTB spillover from wildlife to livestock, and vice versa, although the environmental pathways and frequency need to be determined. Hence, measures to mitigate against such transmission events may be required in order to protect local populations and their livestock living at the periphery of transfrontier conservation in the southern African region.

\section{East Africa}

Eastern Africa (see Fig. 1b) comprises a diversity of countries and ecological zones, but is primarily a moist to dry savannah ecosystem. Agriculture and settlement have encroached on the dry grasslands, where most livestock occur, putting considerable pressure on the resilience of these biological com- munities and land degradation is increasing as a result [48]. In many of the low rainfall zones the livestock and wildlife share the same space, usually at different times, which reduces the chance of direct physical contact. Here, overall densities of wildlife and livestock are relatively low, except in Ethiopia where cattle densities are locally very high, and infectious diseases tend towards endemicity. In some cultures large cattle aggregations occur seasonally (e.g. southern Sudan), and wildlife can locally reach high densities where mass migrations still occur (e.g. southern Sudan and in the Greater Serengeti-Mara ecosystem of Kenya and Tanzania). These conditions create frequent, even if indirect, contacts possibly leading to disease spread and pathogen spillover between species. There are few wildlife populations which are fenced or artificially supplemented, leading to high densities, but also mostly preventing contact between wildlife and livestock. Eastern Africa contains $>50 \%$ of the total African livestock population. Wildlife-livestock interactions occur at low frequency and predominantly at unfenced areas. Most contacts are indirect through the environment, at water points and key forage resource areas, and are seasonally related. 
In the East African region, the evidence generally suggests low prevalence of bTB in both wild $[49,50]$ and domestic animals, with notable exceptions in intensive husbandry systems (dairy) in some countries such as Ethiopia, Uganda and Tanzania [51, 52] and in pastoral systems in Uganda [53, 54]. The spillover of bTB into humans in the region is poorly documented [28], and Ugandan studies report an above global average of $\sim 3 \%$ of human TB infection [54-56]. In Ethiopia, despite the very high prevalence of extrapulmonary TB (EPBT) in humans, which is suggestive of bTB infection, M. bovis was only isolated in 4/964 EPTB patients [52, 57]. Three out of 173 pulmonary TB patients were $M$. bovis positive, and none of the suspected lymphadenitis TB cases were positive in another study among pastoralists in close physical contact with livestock in south-east Ethiopia [58]. The disease is not a high priority for veterinary services, except in the dairy sector, but data is lacking.

Historically, bTB has been a concern in Queen Elizabeth National Park in Uganda [13], affecting a range of wildlife species, with buffalo as a maintenance host. Recently bTB has caused detectable mortality in kob (Kobus kob thomasi): 12 deaths suspected to be due to bTB were reported in one locality, and a further eight noticeably sick kobs were observed and sampled over a period of 1 month from the same population (P. Atemnedi, personal communication, 2011). Overall, the decline in ungulate populations susceptible to bTB in the park is of concern, but the contribution of disease to this trend or the drivers for this are not known. Lion populations have also declined (R. Bengis, personal communication, 2012) but underlying causes (possibly disease or poaching) have not been conclusively determined. Bovine TB infection of buffalo and baboons has also been confirmed in Kenya [59, 60] and several wildlife species have been found positive to serological rapid tests in Ethiopia [50].

\section{Central Africa}

Boukary et al. [33] recently reviewed bTB studies in domestic stocks in sub-Saharan Africa. Only seven studies were related to bTB in livestock in Central African countries, and the reported prevalence in individual cattle ranged from $0 \cdot 2 \%$ to $19 \cdot 9 \%$ depending on the surveillance method adopted. The results also depended on the age of the animals tested and the type of production system considered, and on the breed of cattle tested [61-63]. No published information is available, to our knowledge, on bTB in wildlife populations, and according to the OIE database [30] only one 'suspected' bTB case in wildlife was reported (in Equatorial Guinea) for the period 2007-2012.

Wild ungulates (including African buffalo) still persist mainly in savannah ecosystems of southern Chad, North Cameroon and the Republic of Central Africa, and these largely decimated populations may be exposed to bTB spillover from livestock. In forest ecosystems, no study has been published on wildlifelivestock interactions, especially between forest buffalo and cattle. Wildlife-livestock interactions may be expected to be less frequent than in other parts of the continent because densities of both livestock and wildlife are lower and access to water usually does not represent a limiting factor in these forest ecosystems.

\section{West Africa}

Very little data has been published on bTB in wildlife for West African countries (Fig. 1b). According to the OIE database [30] only one 'suspected' bTB case in wildlife was declared (in Niger) for the period 2007-2012. For livestock populations, the studies that have estimated bTB prevalence in West Africa revealed significant variations according to the areas and the production system considered [33, 64-66]. Low bTB prevalence was estimated in the Torodi region of Niger $(0 \cdot 8 \%$ comparative intra-dermal skin test positive [67]) and at Bamako's abattoir in Mali (1.8\% with symptomatic gross lesions [68]). The highest bTB prevalence in cattle was found in periurban areas, in Ghana (13.8\% comparative intradermal skin test positive [69]) and in Mali (Bamako, $19 \%$ prevalence comparative intra-dermal skin test positive [70]). The economic loss incurred by cattle dealers due to bTB infection in cattle was estimated at US\$1 million in Togo in 1985, based on the meat condemned at abattoirs because of the presence of bTB lesions [71].

In West Africa, bTB thus appears to infect livestock populations with a prevalence similar to other African regions depending on the type of livestock production system (i.e. higher in peri-urban $v s$. extensive systems [67]). In addition, as for Central Africa, no reliable data is available regarding wildlife. This may reflect the absence of the disease in wildlife or it may be due to the absence of appropriate surveys to detect it. The abundance and distribution of most wildlife 


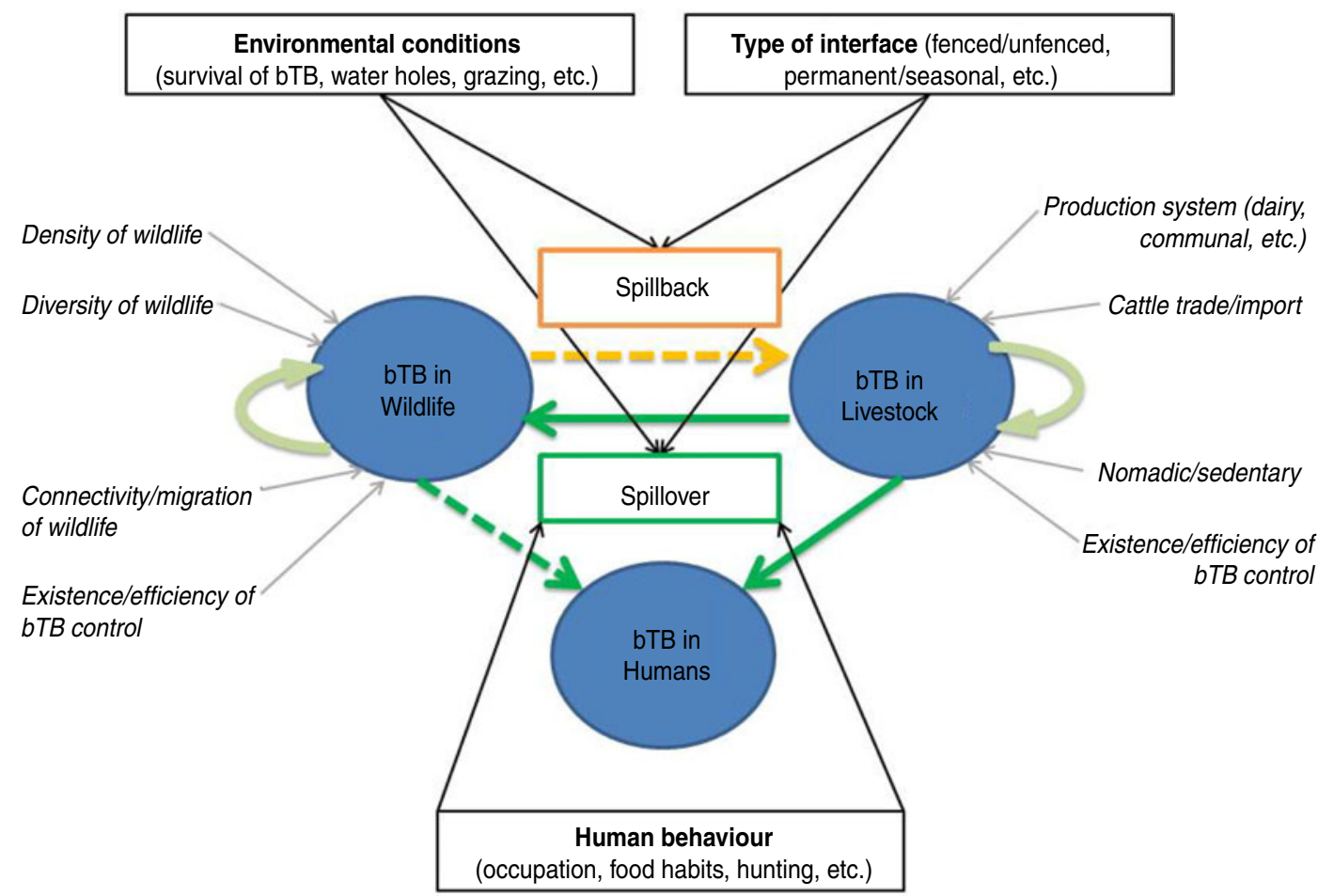

Fig. 2 [colour online]. Interspecific transmission of bovine tuberculosis (bTB) at wildlife-livestock-human interfaces in Africa. Bovine TB can be maintained in livestock (bTB in livestock) and in wildlife (bTB in wildlife), promoted by factors indicated in italics with a grey arrow (e.g. diversity of wildlife, production system). Risks of bTB spillover from livestock to wildlife or humans, and spillback from wildlife to livestock, are indicated in boxes with black arrows (e.g. environmental conditions, human behaviour, etc.).

populations have markedly decreased in West Africa during recent decades [72] due to over-harvesting of wildlife and increasing human populations in the periphery of protected areas [73]. For example, African buffalo populations only persist in a handful of protected areas, where buffalo-cattle interactions appear to be very infrequent [72]. The small size of remaining wildlife populations and their reduced distributions suggest that they are unlikely to act as a maintenance host or significant sources of bTB for cattle. In West Africa, bTB seems to be widespread and poorly controlled in cattle populations, and there is a risk that bTB could spillover to naive and locally endangered wildlife populations.

\section{EPIDEMIOLOGY OF bTB AT AFRICAN WILDLIFE-LIVESTOCK-HUMAN INTERFACES}

\section{Conceptual model of bTB transmission at the wildlife-livestock-human interface}

A disease reservoir may consist in a maintenance population or community (i.e. with more than one species involved) within which a given pathogen can be maintained and which acts as a potential source of infection for a target species [74]. In the case of bTB in Africa, maintenance populations have been identified as cattle, lechwe and buffalo. The existence of a maintenance community remains unknown. The role played by other wild ungulate species, such as the greater kudu and the common warthog, is still debated although in theory, they could connect reservoir (e.g. buffalo) and target (e.g. naive cattle) populations, and so contribute to the maintenance community of bTB. Similarly, the maintenance community created by sympatric cattle and buffalo populations in frequent contacts may allow bTB spillover or spillback, and could act as a source of bTB for other target populations.

Within this maintenance community framework, bTB epidemiology may be represented as a dynamic multi-host system with three main 'compartments', namely wildlife, livestock and humans (Fig. 2). Bovine TB infections may be maintained (independently or not) within livestock populations and within wildlife populations, whereas human infections result from pathogen spillover from animals [75], and very 
rarely from human-to-human transmission [76]. In the following sections we review the main risk factors of bTB infections within the livestock and wildlife compartments, and identify the main drivers of interspecific transmission of bTB ('spillover' and 'spillback' [26]; Fig. 2) at wildlife-livestock-human interfaces in Africa.

\section{Livestock as a source of bTB: spillover to wildlife and humans}

The main bTB risk factors in African cattle populations (see Fig. 2; adapted from [33, 53, 77-81]) include the type of production system (intensive, dairy farms, use of upgraded B. taurus breeds), animal movements (herds importing animals, transhumance) and absence or inefficiency of bTB surveillance and control.

Several studies have analysed bTB risks of transmission between livestock and humans $[58,67,75$, 80,82 ], identifying husbandry practices (housing, mixing cattle herds with other small ruminants), food preferences (consumption of raw or soured milk) and overall health and hygienic conditions (HIV) as the main risk factors for humans (Fig. 2). The role of livestock as a source of infection for humans has been relatively well documented and established in Africa $[51,58,82]$. It should be noted that these studies rarely determined with certainty (i.e. using molecular techniques) the animal source and the routes of transmission [54, 83-85]. In addition, it has been shown that several livestock species other than cattle may be infected by $M$. bovis in African conditions (e.g. camels in Kenya and Ethiopia [86, 87]) although apparently with lower prevalence than cattle (e.g. camels and goats in pastoralist herds in Ethiopia [58]), but the epidemiological role that they might play in bTB multispecies systems remains unexplored.

Although bTB is currently established in several wildlife populations from several sub-Saharan African countries, the introduction of $M$. bovis into a community of free-ranging wild animals has been best documented in KNP, South Africa. The disease was first diagnosed in the early 1990s in the African buffalo population in the southern part of the park [5]. The primary source of the pathogen is believed to have been an infected cattle population in the Komatipoort/Malelane region [88], located south of the Crocodile River, which forms the southern border of the park. Direct (or indirect) spillover from cattle to buffalo must have occurred in or prior to 1960 according to phylogenetic analyses of isolated strains. The genetic characterization of bTB strains isolated from wildlife in KNP indicated a common source in the African buffalo, followed by clonal expansion of the strain [40]. We have no indication of the route of transmission for this initial spillover of bTB from cattle to buffalo, but it is believed that they may have entered into close contact, sharing water and grazing resources at this unfenced interface. It is also speculated that only a limited number of transmission events between cattle and buffalo have occurred, as the disease took a long time to spread to other buffalo herds within the park.

Although detailed documentation of transmission risks only exists for South Africa and Uganda, we suggest that the main risk factors potentially leading to bTB spillover (Fig. 2) may be related to: (i) the type of wildlife--livestock interface (absence of physical separation such as fence, allowing for repeated and prolonged direct or indirect contacts); (ii) the environmental conditions, leading to competition/sharing of common resources (water and grazing) and also compatible with the persistence of $M$. bovis in the environment.

\section{Wildlife as a source of bTB: spillback to livestock or spillover to humans}

So far, two free-ranging mammal species have been demonstrated to play a role as maintenance hosts in natural conditions, the African buffalo in KNP, South Africa [14] and the lechwe in the Kafue basin, Zambia [34, 36]. Two other species, greater kudu and common warthog, are also considered as potential maintenance hosts [42], but no published data exist to confirm this. Since its introduction during the 1960s, bTB has increased its host range by infecting at least 14 species of wild mammals within the boundaries of the Greater KNP Complex [35] including a sporadic case in a bushbuck (Tragelaphus scriptus) [42]. The epidemiology of bTB in African wildlife has been described as a multi-species hostpathogen system [47, 88]. Although many of the mechanisms involved remain uncertain, the main risk factors leading to introduction and maintenance of the infection in a wildlife population (Fig. 2) are probably linked with species diversity (maintenance or spillover hosts), social behaviour of wildlife hosts, wildlife densities (threshold population/community densities), movements of animal populations (possible introduction through migratory individuals, 
confinement), and absence or inefficiency of wildlife bTB surveillance and control.

Few studies in Africa have specifically investigated the transmission of bTB from wildlife to livestock (spillback; Fig. 2). Although other diseases have been demonstrated to occasionally spread from KNP wildlife to neighbouring cattle populations (e.g. [25]), so far no suspected cases of bTB spillback from wildlife to cattle living in contact with the KNP fence have been confirmed using gold-standard techniques. In 2008, the main bTB strain circulating in KNP buffalo populations was demonstrated to have spread to the GNP buffalo population in Zimbabwe [37]. However, several surveys carried out in the surrounding communal lands indicated that bTB has not infected the cattle population [89]. Factors associated with bTB spillover from livestock to wildlife (see above [90]) should also influence bTB spillback from wildlife to livestock (Fig. 2). The main risk factors are thus linked with: (i) the type of interface (fence, herding practices) and the distribution of resources (water and grazing), which directly influence contact patterns between livestock and wildlife; (ii) the environmental conditions, which directly influence the persistence of bTB in the environment. It is therefore of paramount importance to further understand the spatio-temporal overlap between buffalo and cattle (and other reservoir hosts) [89].

Human infections with $M$. bovis from infected wildlife, acquired through ingestion or aerosol exposure, have been described only sporadically as an occupational and recreational hazard, mainly for wildlife veterinarians, hunters, taxidermists and people preparing and consuming venison [91]. To our knowledge, no cases have so far been described in Africa of $M$. bovis in people that are likely to have originated from wildlife, although specific investigation has been lacking at the wildlife-human interface, except in KNP [92]. We assume that the zoonotic risks associated with wildlife bTB (Fig. 2) are similar to those involved in bTB spillover from livestock, mainly related to human behaviour and activities: occupation (national park staff, veterinarians), dietary habits (venison consumption) or leisure (hunting, ecotourism).

\section{Ecology of bTB transmission in Africa: source or sink in multi-host systems?}

Transmission of $M$. bovis at wildlife-livestock-human interfaces in sub-Saharan Africa is driven by biological, ecological and anthropological processes.
Spillover, and spillback, events between wildlife and the two other compartments are probably relatively rare in Africa, with the limited interfaces prevailing in most African countries, but many aspects of this complex system are not well understood.

It is often difficult to accurately study the dynamics of pathogen spread in bTB outbreaks in livestock due to the implementation of control measures such as test-and-slaughter. In wildlife populations, it is mostly unknown when the pathogen was introduced and the situation may be further complicated by mixed and ongoing introductions from multiple sources. However, the bTB epidemic in KNP offers a unique opportunity to study the epidemiology of a single strain of this multi-host pathogen in a multi-species environment in the absence of human control interventions. Following its introduction into the naive buffalo population of KNP, M. bovis spread mainly between buffalo herds and spilled over into at least 13 other species [42], the true extent of which is unknown as bTB monitoring and surveillance in wildlife are most effective in the more visible species showing signs of disease, and where active surveillance has taken place (mainly in buffalo). Molecular analysis of M. bovis isolates from affected herbivores, predators and omnivores was able to provide evidence for direct $M$. bovis transmission (e.g. between predator and prey) but also for indirect transmission (e.g. between buffalo and kudu [40]). Bovine TB epidemiology in wildlife is thus a complex multi-host pathogen system [88], partly driven by resource selection and spatial ecology of wild herbivores sharing common resources and by predator-prey interactions.

As bTB can be transmitted between (wild and domestic) hosts through indirect contact with the contaminated environment (e.g. grass, trees, water, faeces [93]), there is also a possibility that contact patterns between wildlife and livestock may result in directional bTB transmission, with spillback being prevented or likely to occur with a lower probability than spillover transmission. Cattle and buffalo may share the same space and resources, but not at the same time/season, and this temporal shift in use (e.g. night/day, season) may result in different risks of disease transmission through indirect contact if the survival of the bacteria in the environment differs according to time/season. In southern Africa, for instance, cattle are commonly confined in kraals at night and driven during the day by herders who decide to a large extent in which area cattle herds will graze and at which water hole they will drink, while buffalo 
roam freely. In addition, differential grazing behaviour between livestock and wildlife (e.g. avoidance of sites contaminated by faeces or different preferences for feeding patches) may also result in directional bTB transmission. This could explain why the dominant parental KNP strain has spread to buffalo populations within KNP and even to GNP in Zimbabwe, while current evidence suggests that it has not spilledback to cattle populations adjacent to KNP or GNP. Similarly, indirect buffalo-cattle contacts and active test-slaughter control in the buffalo population of Hluhluwe-Umfolozi National Park (South Africa) could explain why bTB strains have spilled over from cattle to buffalo, as indicated by molecular analysis [36], while spillback from buffalo to cattle or human populations has not been reported to date.

Currently, even in southern Africa, bTB spillback from wildlife to livestock (and humans) has not been confirmed. But indirect contacts between cattle and buffalo do occur at the periphery of several large conservation areas in southern Africa, where no efficient fences separate conservation areas from adjacent communal lands. This could lead to a situation where domestic and wildlife reservoirs co-exist, creating a complex maintenance system that would be more difficult to control [74]. In addition, wild spillover hosts, which are considered as unable to maintain bTB infection alone, could play a crucial epidemiological role as 'bridge' species, between the wild and domestic compartments. For instance impala (Aepyceros melampus), although rarely infected by bTB [42], and greater kudu or common warthog (considered as potential maintenance hosts [42]), are relatively abundant at wildlife-livestock interfaces and relatively tolerant of human activities. As these species use common water or food resources, they could potentially transmit bTB infection in both directions, although this has not been demonstrated so far.

\section{MANAGEMENT AND CONTROL OF BTB AT WILDLIFE-LIVESTOCK-HUMAN INTERFACES}

\section{Why control bTB in wildlife?}

Bovine TB is an alien disease in African wildlife [21], and there are numerous reasons that could justify implementing control measures in wildlife populations: impacts on conservation objectives/ endangered species, tourism, wildlife trade, risk of spillback to livestock and spillover to humans. As it is a slow progressive and zoonotic disease, with limited tools for diagnosis and control, it makes sense to act proactively to prevent it from entering wildlife populations. Once M. bovis has been introduced in a wildlife population, it is very difficult to control the disease [31, 90]. Consequently, every effort should be made to protect wildlife populations that are not infected, by reducing the risk of spillover from livestock.

\section{What are the control options for bTB in African wildlife}

The KNP example does help in understanding the complex environment in which we are trying to control the disease in wildlife populations. Due to the expense and difficulty of diagnosing TB in wildlife (non-validated tests and expense of immobilizing) it is impossible to apply test-and-slaughter approaches in large open ecosystems. In smaller parks like Hluhluwe-Umfolozi where herds are in distinct confined areas, test-and-slaughter has been implemented, resulting in a reduction of bTB incidence in the buffalo population but not in the eradication of the disease [94]. Although fences may have severe negative ecological and socio-cultural impacts, they keep buffalo and cattle separated most of the time, which efficiently reduces the risks of disease spillover [25]. However, when fences are damaged, buffalo and/or cattle may cross the boundaries of the protected area, increasing these risks. In the far northern region of KNP adjoining Mozambique and southern GNP there are no fences and spatial overlap between cattle and buffalo is a regular event. However, there is field evidence that buffalo and cattle do not mix readily. This also applies to buffalo that leave the fenced areas to the west of KNP, as most records of escaped buffalo are in areas where there are no cattle, pointing to possible active avoidance of close contact (State Veterinary Skukuza, personal communication).

\section{Lessons learned from past and current measures/strategies}

Once bTB was diagnosed in KNP in 1990, management conducted regular surveys in buffalo herds throughout the park. The disease was confined to the south of the park (south of the Sabie River) in 1992, but surveys carried out in 1994, 1996 and 1998 clearly demonstrated that the disease was spreading northwards through inter-herd transmission. By 2005, it had reached buffalo in the far northern part of the 
park (D. Keet, internal State Veterinary Report, 2005). In 2008, it was diagnosed in GNP in southern Zimbabwe. Various control methods were discussed, including culling all buffalo south of the Sabie River and putting up a fence to the north of known bTB herds. Even complete eradication of buffalo and restocking was considered but the ecological impact was considered more serious than the risk taken by not being able to fully eradicate the disease. In the last decade numerous studies have been conducted to determine the longitudinal impact of bTB in buffalo and no population effect in buffalo [95]. A similar study is now being conducted in lions in KNP [96].

Limited attention has been paid to the risk and incidence of spillback of bTB from buffalo to livestock, but bTB tests conducted in cattle to date to the west of KNP and southern Zimbabwe [89] have failed to confirm bTB in the adjacent areas using gold-standard techniques. Lessons learnt from the KNP example showed that better surveillance in the 1950 s to 1990 s could have resulted in earlier disease detection with a possible test-and-slaughter control strategy. Once bTB has established itself, more localized risk management is the most cost-effective way to prevent spillover and spillback between wildlife and livestock. Fencing would be the primary line of defence to curb bTB spread. In the absence of fences, innovative ways of keeping buffalo and cattle apart should be considered (e.g. herding and kraaling cattle, or manipulation of water availability at the interface and supervised visits to water holes). The effort and impact of bTB control and risk management must also be seen in the context of preventing other livestockrelated diseases from transmitting across the wildlife-livestock interface.

When bTB management and control measures are envisaged, it is important to consider deterministic factors at play in the epidemiology of the disease. Further, the choice of workable control measures and strategies despite being limited for wildlife, should take into account all key factors unique to each different ecosystem. A number of factors have been observed to be associated with bTB in cattle herds [97]. Oloya and co-workers observed that bTB was associated with different types of drinking water sources [53]. The same study also indicated that risks of bTB in cattle are linked to specific geographical regions of production. This implies that bTB control may thus vary according to prevailing ecological conditions. Further, bTB has also been shown to be associated with communal grazing, animal breed and husbandry practices across most of the African continent [97]. Similarly, studies have also shown that herd size has an influence on the prevalence of bTB [79, 98-100]. Taken together, these factors are vital in formulating workable control strategies for cattle bTB across African pastoral communities. However, control measures such as the test-andslaughter schemes used to control bTB in cattle populations are impractical in free-living wildlife populations. Nevertheless, at the livestock-wildlifehuman interface more detailed studies are needed to understand both key and proxy factors related to the maintenance, spread and transmission of the disease among susceptible hosts. Owing to the impracticality of other control measures, the key factor at the livestock-wildlife-human interface area is to reduce or to completely eliminate interspecies contact. Selective cropping of old, debilitated animals can also be used to remove what may be chronic shedders of the disease. BCG vaccination in buffalo has been shown to provide poor protection [93] and further work on approaches to vaccination is required, including target species, age of vaccinees and new vaccine formulations. BCG vaccination of cattle populations living in contact with wildlife could also be envisaged in order to prevent or reduce the risks of bTB spillback and spillover, but there is also a need to evaluate the efficiency of such control strategies. However, given the lack of scientific data and resources of most developing countries, the use of vaccines is impracticable at the moment. A more feasible option is the creation of double fences or buffer zones (e.g. with limited and managed grazing of livestock, with wildlife hunting activities), with a zone where there is sufficient distance to avoid environmental contamination with $M$. bovis.

\section{Perspectives for a one health approach}

Studies on bTB in Africa have so far focused rather narrowly, either on livestock, wildlife or human health research in separate compartments. Systems-based research involving both the animal and the public health sector have rarely been undertaken [92]. Despite decades of research on bTB, there is still very little information on the epidemiology of bTB in Africa. Important knowledge gaps include the strains involved in humans and animals in the same areas, spillover and spillback dynamics, quantification of risk factors of disease transmission between wildlife-livestock-humans, impact of bTB on animal health and animal productivity and livelihoods, 
impact on conservation and dynamics of wildlife population. The absence of this information probably reflects the apparently low incidence of bTB in humans, and of bTB transmission between wildlife and livestock, although this picture may change given increasing overlap at the interface between species in many parts of Africa. Due to the nature of the disease (multi-host pathogen with impact on humans, animals and ecosystem health), collaboration between the public and animal health sectors, including wildlife specialists, is important from a sanitary, and probably also from an economic, point of view. Integrated research is paramount to gain a better understanding of the epidemiology of bTB at the human-livestock-wildlife interface, to be able to quantify the impact of the disease and to propose adequate and sustainable control approaches.

\section{CONCLUSIONS, KNOWLEDGE GAPS AND THE WAY FORWARD}

The information collated in this review confirms that bTB is widespread in livestock on the African continent [32], whereas bTB infection of wildlife, which was historically limited to a few countries in southern and eastern Africa (South Africa, Tanzania, Uganda, Zambia) may be spreading in southern Africa (Mozambique [30], Zimbabwe [37]). Although the impact of bTB may be significant in Africa, affecting the economy, the ecosystem and human health [28], wildlife TB is currently not considered a priority for most African countries. M. bovis has been isolated from a wide range of wild free-ranging mammals, including maintenance hosts in natural conditions, which will considerably complicate future bTB control programmes [101], and possibly compromise the chances of eradication in sub-Saharan African countries. But to date, to our knowledge, no cases have been documented in sub-Saharan Africa demonstrating $M$. bovis spillback from infected wildlife to cattle or spillover to human populations.

Currently, bTB in African wildlife south of the Sahara is essentially a conservation issue, with social, welfare and economic implications for the affected areas/countries. Although the ecological impacts of bTB on infected free-ranging populations is still not clearly demonstrated (even for buffalo [102] or lions [96]), there is concern in southern Africa that transboundary animal diseases spread by wildlife, and bTB in particular, may negatively impact on economic activities and livelihoods of local people, especially in the context of transfrontier conservation areas initiatives [35]. In other parts of Africa, it is likely that the risk of bTB transmission between wildlife and livestock (and possibly humans) will increase in the near future, with ever-increasing human encroachment into wildlife habitats due to the demand for grazing and cropping land, and possibly through dissemination of bTB-positive upgraded livestock into rural areas (e.g. dairy cattle breeds in Ethiopia). This will have serious consequences for biodiversity conservation, as bTB may potentially further threaten several small and isolated wildlife populations (including endangered species at a local or global scale), and also potentially for veterinary and public health as the wildlife reservoir will complicate future bTB control or eradication programmes.

Several major knowledge and technical gaps must be addressed before effective long-term control of bTB at the wildlife-livestock-human interface in Africa can be put in place. The first gap in knowledge relates to the absence of understanding of the role of individual wildlife species/populations in the epidemiology of bTB in complex multi-host systems [88]. This also applies to several livestock species other than cattle, like goats and pigs, which can be infected by bTB but for which no information is available on the role they play in the epidemiology of the disease in sub-Saharan African contexts. Despite recent conceptual [103] and methodological (e.g. [104]) developments, there is a general lack of longitudinal data (with the exception of South Africa). Longitudinal surveys are needed in order to monitor the (temporal) dynamics of the infection, and also to provide $M$. bovis isolates from African wildlife populations. These isolates are needed to elucidate the epidemiological role of the various species and the relationship between the wild and domestic host populations. The second knowledge gap relates to the absence of understanding of the ecological and anthropogenic drivers of contacts between wildlife and livestock (see [89]), and humans, potentially leading to bTB transmission. Recent advances in telemetry have improved our understanding of the movements of free-ranging animals, but there is a need for multidisciplinary approaches bringing together ecology, sociology and epidemiology in order to identify the main drivers of contacts, and to investigate how the manipulation of shared resources might mitigate the risks of disease transmission. The third knowledge gap concerns environmental source of $M$. bovis, and the persistence of infectious material in various 
African ecosystems. Previous studies have given contrasting results [44, 45], and there is need for more thorough investigations in the future, as the importance of indirect transmission in the epidemiology of bTB remains elusive.

Improving surveillance and control of bTB at African wildlife-livestock-human interfaces also requires accurate, affordable and reliable diagnostics, as the performance of existing tests is unknown for most wild African species. However, this technical limitation will probably remain a major challenge because the veterinary bTB diagnostic market is very small, and virtually non-existent for (African) wildlife [105]. In addition, new developments in the field are often not suitable for developing countries, either because they require sophisticated laboratory infrastructure and/or well-trained personnel [28]. In the long term, the development of effective vaccines could significantly contribute to protecting targeted wildlife populations and/or maintaining bTB prevalence below a threshold that would reduce the risk of spillback to livestock. A BCG vaccine has shown some promise in badgers in Europe [106]. BCG vaccine failed to protect African buffalo against bTB in an initial study [107]. Nevertheless, the potential longterm benefit from reducing the infection pressure through vaccination of maintenance hosts warrants further investigation. BCG vaccination of cattle populations living in contact with wildlife could also be envisaged in order to prevent or reduce the risks of bTB spillback and spillover, but there is also a need to evaluate the efficiency of such strategies.

From a wider mycobacterial perspective, we also acknowledge that $M$. tuberculosis remains a greater risk to African human populations than M. bovis. In addition, there are several other animal diseases that have more significant direct or indirect detrimental impacts on livestock at wildlife-livestock interfaces in Africa (e.g. corridor disease and foot-and-mouth disease). The effort and resource allocation required to control the threat of bTB at the wildlife-livestockhuman interface should therefore be linked to other critical transdisciplinary programmes aiming at improving the health of humans and their livestock and associated wildlife.

\section{ACKNOWLEDGEMENTS}

We thank the organizers of the 1st Wildlife Tuberculosis Conference, held 9-12 September 2012 in Kruger National Park, South Africa, for the opportunity to gather first-hand information on the latest developments regarding wildlife bTB. This work was conducted within the framework of the Research Platform 'Production and Conservation in Partnership' (RP-PCP) and the Animal and Human Health Environment and Development initiative (AHEAD). M.dG.W and A.C. were supported by the Ministère Français des Affaires Etrangères through the French Embassy in Zimbabwe (RP-PCP grant 2008-2012), and R.T. by the Swiss National Science Foundation.

\section{DECLARATION OF INTEREST}

None.

\section{REFERENCES}

1. Schmitt SM, et al. Bovine tuberculosis in free-ranging white-tailed deer from Michigan. Journal of Wildlife Diseases 1997; 33: 749-758.

2. Pfeiffer DU. The role of a wildlife reservoir in the epidemiology of bovine tuberculosis: Massey University, 1994, $456 \mathrm{pp}$.

3. Delahay RJ, The status of Mycobacterium bovis infection in UK wild mammals: a review. Veterinary Journal 2002; 164: 90-105.

4. Aranaz A, et al. Bovine tuberculosis (Mycobacterium bovis) in wildlife in Spain. Journal of Clinical Microbiology 2004; 42: 2602-2608.

5. Bengis RG, et al. An outbreak of bovine tuberculosis in a free-living African buffalo (Syncerus caffer) population in the Kruger National Park: a preliminary report. Onderstepoort Journal of Veterinary Research 1996; 63: 15-18.

6. De Lisle GW, Mackintosh CG, Bengis RG. Mycobacterium bovis in free-living and captive wildlife, including farmed deer. Revue Scientifique et Technique de l'Office International des Epizooties 2001; 20: 86-111.

7. Thoen CO, et al. Tuberculosis: a re-emerging disease in animals and humans. Veterinaria Italiana 2009; 45: 135-181.

8. Nolan A, Wilesmith JW. Tuberculosis in badgers (Meles meles). Veterinary Microbioogy 1994; 40: 179-191.

9. Woodroffe R, et al. Effects of culling on badger abundance: implications for tuberculosis control. Journal of Zoology 2008; 274: 28-237.

10. Coleman JD, Cooke MM. Mycobacterium bovis infection in wildlife in New Zealand. Tuberculosis 2001; 81: 191-202.

11. Ramsey DSL, Efford MG. Management of bovine tuberculosis in brushtail possums in New Zealand: predictions from a spatially explicit, individual-based model. Journal of Applied Ecology 2010; 47: 911-919.

12. Paine R, Martinaglia G. Tuberculosis in wild buck living under natural conditions. Journal of Comparative Pathology and Therapeutics 1929; 42: 1-8. 
13. Woodford MH. Tuberculosis in wildlife in the Ruwenzori National Park, Uganda (Part II). Tropical Animal Health and Production 1982; 14: 155-160.

14. De Vos V, et al. The epidemiology of tuberculosis in free-ranging African buffalo (Syncerus caffer) in the Kruger National Park, South Africa. Onderstepoort Journal of Veterinary Research 2001; 68: 119-130.

15. Smith N, et al. European 1: a globally important clonal complex of Mycobacterium bovis. Infection, Genetics and Evolution 2011; 11: 1340-1351.

16. Müller B, et al. African 1, an epidemiologically important clonal complex of Mycobacterium bovis dominant in Mali, Nigeria, Cameroon, and Chad. Journal of Bacteriology 2009; 191: 1951-1960.

17. Berg S, et al. African 2: a clonal complex of Mycobacterium bovis epidemiologically important in East Africa. Journal of Bacteriology 2011; 193: 670-678.

18. Brosch R, et al. A new evolutionary scenario for the Mycobacterium tuberculosis complex. Proceedings of the National Academy of Sciences USA 2002; 99: 3684-3689.

19. Taylor GM, et al. First report of Mycobacterium bovis DNA in human remains from the Iron Age. Microbiology 2007; 153: 1243-1249.

20. Hutcheon D. Annual Report, Colonial Veterinary Surgeon. Cape of Good Hope, 1880.

21. Bengis RG, Kock RA, Fischer J. Infectious animal disease: the wildlife livestock interface. Revue Scientifique et Technique de l'Office International des Epizooties 2002; 21: 53-65.

22. Bradley DG, et al. Genetics and domestic cattle origins. Evolutionary Anthropology 1998; 6: 79-86.

23. Kock RA. What is the infamous 'wildlife/disease interface?' A review of current knowledge for the African continent In: Osofsky SA, Cleaveland S, Karesh WB et al., eds. Conservation and Development Interventions at the Wildlife/Livestock Interface: Implications for Wildlife, Livestock and Human Health. Gland, Switzerland: IUCN, 2005, pp. 1-13.

24. Bengis RG. Transfrontier conservation area initiatives in Sub-Saharan Africa: some animal health challenges. In: Osofsky SA, Cleaveland S, Karesh WB et al., eds. Conservation and Development Interventions at the Wildlife/Livestock Interface: Implications for Wildlife, Livestock and Human Health. Gland, Switzerland: IUCN, 2005, pp. 15-19.

25. de Garine-Wichatitsky $M$, et al. Consequences of animals crossing the edges of transfrontier parks. In: Andersson JA, de Garine-Wichatitsky M, Cumming DHM, Dzingirai V, Giller KE, eds. Transfrontier Conservation Areas People Living on the Edge. New York and London: Earthscan, 2013, pp. 137-162.

26. Nugent G. Maintenance, spillover and spillback transmission of bovine tuberculosis in multi-host wildlife complexes: a New Zealand case study. Veterinary Microbiology 2011; 151: $34-42$.

27. Cosivi O, et al. Epidemiology of Mycobacterium bovis infection in animals and humans, with particular reference to Africa. Revue Scientifique et Technique de l'Office International des Epizooties 1995; 14: 733-746.
28. Michel A, Müller B, van Helden P. Mycobacterium bovis at the animal-human interface: A problem, or not? Veterinary Microbiology 2009; 133: 335-343

29. Michel AL. Implications of tuberculosis in African wildlife and livestock. Annals of the New York Academy of Science 2002; 969: 251-255.

30. Anon. World Animal Health Information Database (WAHID). World Organisation for Animal Health (OIE), 2012.

31. Anon. HANDISTATUS II. World Organisation for Animal Health (OIE), 2012.

32. Ayele WY, et al. Bovine tuberculosis: an old disease but a new threat to Africa. International Journal of Tuberculosis and Lung Disease 2004; 8: 924-937.

33. Boukary AR, et al. Tuberculosis caused by Mycobacterium bovis in sub-Saharan Africa. Annales de Médecine Vétérinaire 2011; 155: 23-37.

34. Gallagher $\mathbf{J}$, et al. Pulmonary tuberculosis in free-living lechwe antelope in Zambia. Tropical Animal Health and Production 1972; 4: 204-213.

35. Michel AL, et al. Wildlife tuberculosis in South African conservation areas: implications and challenges. Veterinary Microbiology 2006; 112: 91-100.

36. Munyeme M, et al. Tuberculosis in Kafue lechwe antelopes (Kobus leche kafuensis) of the Kafue Basin in Zambia. Preventive Veterinary Medicine 2010; 95: 305-308

37. de Garine-Wichatitsky M, et al. Bovine tuberculosis in buffaloes, Southern Africa. Emerging Infectious Diseases 2010; 16: 884-885.

38. Jori F, et al. Assessment of the occurrence of bovine tuberculosis at the wildlife/livestock interface in two protected areas of Northern Botswana. International Wildlife TB Conference, Skukuza, Kruger National Park, 2012.

39. Alexander KA, et al. Novel Mycobacterium tuberculosis complex pathogen, M. mungi. Emerging Infectious Diseases 2010; 16: 1296-1299.

40. Michel AL, et al. Molecular epidemiology of Mycobacterium bovis isolates from free-ranging wildlife in South African game reserves. Veterinary Microbiology 2009; 133: 335-343.

41. Michel AL, Bengis RG. The African buffalo: a villain for inter-species spread of infectious diseases in southern Africa. Onderstepoort Journal of Veterinary Research 2012; 79: 5 .

42. Bengis RG, et al. Bovine tuberculosis in free-ranging wildlife: a review of global occurrence, pathology and epidemiology of this disease, and potential conservation implications. International Wildlife TB Conference, Skukuza, Kruger National Park, 2012.

43. Woodford MH. Tuberculosis in wildlife in the Ruwenzori National Park, Uganda (Part I). Tropical Animal Health and Production 1982; 14: 81-88.

44. Michel AL, et al. Bovine tuberculosis in African buffaloes: observations regarding Mycobacterium bovis shedding into water and exposure to environmental mycobacteria. BMC Veterinary Research 2007; 3: 23.

45. Tanner M, Michel AL. Investigation of the viability of $M$. bovis under different environmental conditions in 
the Kruger National Park. Onderstepoort Journal of Veterinary Research 1999; 66: 185-190.

46. Ferguson K, Hanks J. A review of the environmental, social and economic impacts of game an veterinary fencing in Africa with particular reference to the Great Limpopo and Kavango-Zambezi Transfrontier Conservation Areas. Pretoria: Mammal Research Institute, 2010.

47. Caron A, et al. Relationship between burden of infection in ungulate populations and wildlife/livestock interfaces. Epidemiology and Infection. Published online: 26 February 2013. doi:10.1017/S0950268813000204.

48. Norton-Griffiths M. How many wildebeest do you need? World Economics 2007; 8: 41-64.

49. Cleaveland $\mathbf{S}$, et al. Tuberculosis in Tanzanian wildlife. Journal of Wildlife Disease 2005; 41: 446-453.

50. Tschopp R, et al. Bovine tuberculosis in Ethiopian wildlife. Journal of Wildlife Disease 2010; 46: 7537562.

51. Cleaveland S, et al. Mycobacterium bovis in rural Tanzania: risk factors for infection in human and cattle populations. Tuberculosis 2007; 87: 30-43.

52. Wondewosen $\mathbf{T}$, et al. Conventional and molecular epidemiology of bovine tuberculosis in dairy farms in Addis Ababa city, the capital of Ethiopia. International Journal of Applied Research in Veterinary Medecine 2010; 8: 143-151.

53. Oloya $\mathbf{J}$, et al. Risk factors for herd-level bovinetuberculosis seropositivity in transhumant cattle in Uganda. Preventive Veterinary Medicine 2007; 80: 318 329.

54. Oloya J, et al. Mycobacteria causing human cervical lymphadenitis in pastoral communities in the Karamoja Region of Uganda. Epidemiology and Infection 2008; 136: 636-643.

55. Asiimwe BB, et al. Mycobacterium tuberculosis Uganda genotype is the predominant cause of TB in Kampala, Uganda. International Journal of Tuberculosis and Lung Disease 2008; 12: 386-391.

56. Makita K, et al. Evidence-based identification of the most important livestock related zoonotic diseases in Kampala, Uganda. Journal of Veterinary Medical Science 2011; 73: 991-1000.

57. Firdessa R, et al. Mycobacterial lineages causing pulmonary and extraulmonary tuberculosis in Ethiopia. Emerging Infectious Diseases (in press).

58. Gumi B, et al. Zoonotic transmission of tuberculosis between pastoralists and their livestock in South-East Ethiopia. EcoHealth 2012; 9: 139-149.

59. Tanner M. Mycobacterium bovis in the wildlifelivestock-human interface of east and southern Africa. International Wildlife TB Conference, Skukuza, Kruger National Park, 2012.

60. Tarara R, et al. Tuberculosis in wild olive baboons, Papio cynocephalus anubis (Lesson), in Kenya. Journal of Wildlife Diseases 1985; 21: 137-140.

61. Goutard F. Epidémiologie de la tuberculose et de la brucellose des bovins en zone périurbaine d'Abéché, Tchad. Revue d'Elevage et de Médecine Vétérinaire des Pays Tropicaux 2002; 55: 5-13.
62. Schelling E, et al. Molecular epidemiology of first mycobacteria isolates from animals in Chad. Epidémiologie et Santé Animale 2005; 48: 81-91.

63. Ngandolo BN, et al. Ante- and postmortem diagnostic of bovine tuberculosis from cattle at slaughterhouses in Southern Chad. Revue d'Elevage et de Médecine Vétérinaire des Pays Tropicaux 2009; 62: 5-12.

64. Gidel R, et al. A survey on bovine tuberculosis in several regions of Western Africa (Haute Volta and Côte d'Ivoire) using tuberculin tests. Revue d'Elevage et de Médecine Vétérinaire des Pays Tropicaux 1969; 22: 337-355.

65. Doutre MP. Note on recent cases of bovine tuberculosis (Mycobacterium bovis) observed at Dakar's slaughterhouse. Revue d'Elevage et de Médecine Vétérinaire des Pays Tropicaux 1976; 29: 309-311.

66. Fofana M. Bovine tuberculosis in Mali: results of an epidemiological survey of dairy farms from periurban areas in Bamako district. Revue d'Elevage et de Médecine Vétérinaire des Pays Tropicaux 2003; 56: 115-120.

67. Boukary AR, et al. Bovine tuberculosis prevalence survey on cattle in the rural livestock system of Torodi (Niger). PLoS ONE 2011; 6: e24629.

68. Müller B, et al. Molecular characterisation of Mycobacterium bovis isolated from cattle slaughtered at the Bamako abattoir in Mali. BMC Veterinary Research 2008; 4: 26.

69. Bonsu OA, Laing E, Akanmori BD. Prevalence of tuberculosis in cattle in the Dangme-West district of Ghana, public health implications. Acta Tropica 2000; 76: 9-14.

70. Sidibé SS, et al. Bovine tuberculosis in Mali: results of an epidemiological survey carried out in dairy farms from periurban areas in Bamako district. Revue d'Elevage et de Médecine Vétérinaire des Pays Tropicaux 2003; 56: 115-120.

71. Thorel MF. Tuberculose. In: Principales Maladies Infectieuses et Parasitaires du Bétail, Europe et Régions Chaudes. Editions Médicales Internationales, Paris, France, 2003, pp. 927-961.

72. Hibert F, et al. Spatial avoidance of invading pastoral cattle by wild ungulates: insights from using point process statistics. Biodiversity and Conservation 2010; 19: 2003-2024.

73. Wittemyer G, et al. Accelerated human population growth at protected area edges. Science 2008; 321 (123126).

74. Haydon DT, et al. Identifying reservoirs of infection: a conceptual and practical challenge. Emerging Infectious Diseases 2002; 8: 1468-1473.

75. Biet F, Guilloteau LA, Boschiroli ML, Thorel MF. Zoonotic aspects of Mycobacterium bovis and Mycobacterium avium-intracellulare complex (MAC). Veterinary Research 2005; 36: 411-436.

76. Michel AL, Müller B, van Helden P. Mycobacterium bovis at the animal-human interface: a problem, or not? Veterinary Microbiology 2010; 133: 335-43

77. Tschopp R, et al. Repeated representative crosssectional skin testing for bovine tuberculosis in cattle in traditional husbandry system in Ethiopia. Veterinary Record 2010; 167: 250-256. 
78. Humblet M-F, Boschiroli ML, Saegerman C. Classification of worldwide bovine tuberculosis risk factors in cattle: a stratified approach. Veterinary Research 2009; 40: 50 .

79. Kazwala RR, et al. Isolation of Mycobacterium bovis from human cases of cervical adenitis in Tanzania: a cause for concern? International Journal of Tuberculosis and Lung Disease 2001; 5: 87-91.

80. Tschopp R, et al. Risk factors of bovine tuberculosis in cattle in rural livestock production systems of Ethiopia. Preventive Veterinary Medicine 2009; 89: 205-211.

81. Gumi B, et al. Prevalence of tuberculin reactors in pastoral cattle herds in the Oromia Region, Southern Ethiopia. Tropical Animal Health and Production 2011; 43: 1081-1087.

82. Mfinanga SG, et al. Mycobacterial adenitis: role of Mycobacterium bovis, non-tuberculous mycobacteria, HIV infection, and risk factors in Arusha, Tanzania. East African Medical Journal 2004; 81: 171-178.

83. Idigbe EO, Anyiwo CE, Onwujekwe DI. Human pulmonary infections with bovine and atypical mycobacteria in Lagos, Nigeria. Journal of Tropical Medicine and Hygiene 1986; 89: 143-148.

84. Mawak JD, et al. Human pulmonary infections with bovine and environment (atypical) Mycobacteria in Jos, Nigeria. Ghana Medical Journal 2006; 40: 132-136.

85. Rasolofo Razanamparany V, et al. Prevalence of Mycobacterium bovis in human pulmonary and extrapulmonary tuberculosis in Madagascar. International Journal of Tuberculosis and Lung Disease 1999; 3: 632-634.

86. Mamo G, et al. Pathology of camel tuberculosis and molecular characterization of its causative agents in pastoral regions of Ethiopia. PLoS ONE 2011; 6: e15862.

87. Paling RW, et al. The occurrence of infectious diseases in mixed farming of domesticated wild herbivores and livestock in Kenya. II. Bacterial diseases. Journal of Wildlife Disease 1988; 24: 308-316

88. Renwick AR, White PC, Bengis RG. Bovine tuberculosis in southern African wildlife: a multi-species hostpathogen system. Epidemiology and Infection 2007; 135: 529-540.

89. de Garine-Wichatitsky M, et al. Measuring contacts between African buffalo and domestic cattle in the Great Limpopo Transfrontier Conservation Area: implications for modelling bovine tuberculosis spill-over between wild and domestic hosts. International Wildlife TB Conference, Skukuza, Kruger National Park, 2012.

90. Munyeme M, et al. Prevalence of bovine tuberculosis and animal level risk factors for indigenous cattle under different grazing strategies in the livestock/wildlife interface areas of Zambia. Tropical Animal Health and Production 2009; 41: 345-352.

91. Liss GM, et al. Occupational exposure to Mycobacterium bovis infection in deer and elk in Ontario. Canadian Journal of Public Health 1994; 85: 326-329.

92. Weyer K, et al. Mycobacterium bovis as a zoonosis in the Kruger National Park, South Africa. International Journal of Tuberculosis and Lung Disease 1999; 3: 1113-1119.
93. Courtenay O, et al. Is Mycobacterium bovis in the environment important for the persistence of bovine tuberculosis? Biology Letters 2006; 2: 460-462.

94. Cooper D. Bovine tuberculosis control in the Hluhluwe iMfolozi Park 1999-2012. International Wildlife TB Conference, Skukuza, Kruger National Park, 2012.

95. Cross PC, et al. Disease, predation and demography: assessing the impacts of bovine tuberculosis on African buffalo by monitoring at individual and population levels. Journal of Applied Ecology 2009; 46: 467-475.

96. Ferreira S, Hofmeyr M, Funston P. The trouble with bovine tuberculosis and lions. International Wildlife TB Conference, Skukuza, Kruger National Park, 2012.

97. Omer MK, et al. A cross-sectional study of bovine tuberculosis in dairy farms in Asmara, Eritrea. Tropical Animal Health and Production 2001; 33: 295-303.

98. Ameni G, Amenu K, Tibbo M. Bovine tuberculosis: prevalence and risk factor assessment in cattle and cattle owners in Wuchale-Jida district, Central Ethiopia. International Journal of Applied Research in Veterinary Medicine 2003; 1: 1-13.

99. Cook AJC, et al. Human and bovine tuberculosis in the Monze district of Zambia-a cross-sectional study. British Veterinary Journal 1996; 152: 37-46.

100. Firdessa R, et al. High prevalence of bovine tuberculosis in dairy cattle in central Ethiopia: implications for the dairy industry and public health. PLOS ONE 2012; 7: e52851.

101. De Lisle GW, et al. Tuberculosis in free-ranging wildlife: detection, diagnosis and management. Revue Scientifique et Technique de l'Office International des Epizooties 2002; 21: 317-334.

102. Caron A, Cross PC, du Toit JT. Ecological implications of bovine tuberculosis in African Buffalo herds. Ecological Applications 2003; 13: 1338-1345.

103. Caron A, de Garine-Wichatitsky M, Morand S. Using the community of pathogens to infer inter-specific host epidemiological interactions at the wildlife/domestic interface. In: Morand S, Beaudeau F, Cabaret J, eds. New Frontiers in Molecular Epidemiology of Infectious Diseases. Heidelberg: Springer, 2012, pp. 311-332.

104. Hlokwe TM, et al. Evaluation of the discriminatory power of variable number of tandem repeat (VNTR) typing of Mycobacterium bovis isolates from Kruger National Park. International Wildlife TB Conference, Skukuza, Kruger National Park, 2012.

105. Chambers MA. Diagnostics. International Wildlife TB Conference, Skukuza, Kruger National Park, 2012.

106. Corner LA, et al. Vaccination of European badgers (Meles meles) with BCG by the subcutaneous and mucosal routes induces protective immunity against endobronchial challenge with Mycobacterium bovis. Tuberculosis 2008; 88: 601-609.

107. de Klerk LM, Michel A, Bengis R, Kriek N, Godfroid J. BCG vaccination failed to protect yearling African buffaloes (Syncerus caffer) against experimental intratonsilar challenge with Mycobacterium bovis. Veterinary Immunology and Immunopathology 2010; 137: 84-92. 